\title{
Inhibitory effect of menthol on expression of aspartyl proteinase 1 in fluconazole-resistant Candida albicans
}

\author{
Shahrzad Shayegan, Alireza Khodavandi* (D) \\ Department of Biology, Gachsaran Branch, Islamic Azad University, Gachsaran, Iran
}

\section{ART I C L E IN F O}

Article Type:

Original Article

\section{Article History:}

Received: 15 September 2018

Accepted: 5 November 2018

\section{Keywords:}

Candida albicans

Fluconazole

Menthol

SAP1

\begin{abstract}
A B S T R A C T
Introduction: Fluconazole-resistant Candida albicans is one of the biggest problems seen in clinical practices. One of the most common ways to resolve this problem is the use of natural pure compounds such as menthol. The aims of this study were to investigate the hyphal formation and gene expression profiling of fluconazole-resistant $C$. albicans treated by menthol. Methods: Colonization of vaginal isolates of $C$. albicans was recognized and fluconazole-resistant yeasts detected by WHONET software. The relative minimum inhibitory concentrations (MICs) of menthol were determined by broth microdilution for fluconazole-resistant isolates. The potency of menthol to inhibit hyphal formation was exploited using a light microscope. A quantitative real-time RT- PCR was used to measure the expression of SAP1 .

Results: Almost $100 \%$ of colonized vaginal isolates of C. albicans was found to be fluconazoleresistant. $\mathrm{MIC}_{90}$ for menthol in fluconazole-resistant isolates was 1.6 to $25 \mu \mathrm{g} / \mathrm{mL}$. Furthemore, all isolates treated with menthol showed a significant reduction in hyphae and number of planktonic cells. In the fluconazole-resistance C. albicans cells treated with fluconazole, the expression levels of SAP1 increased by $1.53-(2 \times \mathrm{MIC}$ conc.) and 1.43-fold (1×MIC conc.). However, treatment with menthol down regulated the $S A P 1$ expression by 2.02 - and 1.85 -fold at concentrations of $2 \times$ MIC and $1 \times$ MIC, respectively $(P \leq 0.05)$.

Conclusion: This study suggests that menthol might have potential applications in treatment of infections, due to fluconazole-resistance C. albicans. In addition, SAP1 could be probable molecular target of menthol in C. albicans.
\end{abstract}

Implication for health policy/practice/research/medical education:

Menthol act as anticandidal agent and has the potential for therapy of candidiasis. These results can provide insights into the mechanism of menthol against C. albicans.

Please cite this paper as: Shayegan, S, Khodavandi A. Inhibitory effect of menthol on expression of aspartyl proteinase 1 in fluconazole-resistant Candida albicans. J Herbmed Pharmacol. 2019;8(1):35-40. doi: 10.15171/jhp.2019.06.

\section{Introduction}

A common agent for opportunistic fungal infection of candidiasis is Candida albicans. In fact, candidiasis is a problem of growing clinical importance, particularly in individuals with immunologic (e.g., genetic susceptibility, cancer, organ transplant and human immunodeficiency virus infection) and non immunologic (e.g., pregnancy, neonates and childhood, burn, diabetes and nosocomial infections) predisposing conditions which contribute to enhanced susceptibility to infections (1-3).

Candida albicans has developed virulence factors with specific strategies to allow its successful host tissue colonization. Key virulence factors of C. albicans expressed or required for pathogenesis are secreted aspartyl proteinases (Saps), encoded by a 10-member gene family (SAP1 to SAP10) (3-6). These enzymes with a signal peptide are secreted into the extracellular space. Sap9 and Sap10 are cell wall-associated proteases (7). Based on the amino acid sequence alignments and protein homology, the 10 SAP genes are classified into three subfamilies. The subfamilies consist of the SAP1 to SAP3, SAP4 to SAP6, SAP9, and SAP10 genes (SAP7 and SAP8 are divergent) $(5,6,8,9)$. The proteolytic activity of the Sap proteins could be involved in binding to the host cells and degradation of various host tissue barriers, immune response evasion, facilitate the nutrient availability for fungal growth from host protein digestion, adhesion and survival of fungal cells within host cells $(10,11)$. Several studies have described differential expression of SAP family, in vitro and in vivo, during candidiasis (4-6). The 
expression pattern of these genes in the pathogenesis of $C$. albicans infection are associated with a number of other putative virulence factors of $C$. albicans including hypha formation, adhesion and phenotypic switching. Therefore, the expression of $S A P$ genes varies at different stages of fungal growth and disease $(3,5,6)$. Identification of $S A P 1$ gene was done by Hube et al (12) and characterization of the protein product by White et al (13). Sap1 enzyme related to yeast cell form is activiated in an acidic $\mathrm{pH}$ environment. Expression of SAP1 is strain-specifc and it has been shown that Sap1 contribute significantly to mucosal infections $(5,6,9,14)$. Sap1 is produced during growth in media containing proteins as the sole nitrogen source. Furthermore, SAP1 mutants of C. albicans grew slowly after induction in proteinase-inducing medium and the production of their own proteinases were delayed compared with the parental wild type strain. The virulence of mutant strains lacking SAP1 gene slightly reduced in animal models of candidiasis (14).

The widespread use of antifungal therapy has been associated with a marked increase in the incidence of treatment failures in candidiasis patients resulting from antifungal drug resistance with a serious threat to life $(15,16)$. Recently, natural pure antifungal compounds derived from plants, such as menthol, have received a great deal of attention. Menthol $\left(\mathrm{C}_{10} \mathrm{H}_{20} \mathrm{O}\right)$ is a terpenoid compound of the Mentha genus in the Lamiaceae family. Results from several studies show that menthol possesses an antifungal activity (17-20). Menthol exerts its antifungal activity on the cell membrane permeability and the cell wall consistency, hence probably causing cell death or inhibiting the filamentation of C. albicans $(18,21)$. The aim of the prresent study was to evaluate the antifungal effect of menthol against fluconazole-resistant C. albicans vaginal isolates in pregnant women. In particular, we performed antifungal susceptibility, hypha formation and gene expression profiling of $C$. albicans treated with menthol.

\section{Materials and Methods}

Microorganisms

Via vaginal swabs, 30 isolates of $C$. albicans were obtained from 100 healthy pregnant women who admitted in Ahvaz Imam Khomeini hospital affiliated to Jundishapur University of Medical Sciences, Ahvaz, Iran. Isolates were grown in Sabouraud Dextrose Agar (SDA, Biolife, Italy) at $37^{\circ} \mathrm{C}$ for 24 hours and identified by wet mount microscopy, Gram stain, macroscopic morphology on SDA and CHROMagar ${ }^{\mathrm{TM}}$ Candida (CHROMagar, France) and germ tube formation in human serum. Quality control strains of C. albicans ATCC 14053 and fluconazoleresistant C. albicans ATCC MYA-573 were also employed. Stock cultures of $C$. albicans were maintained at $-75^{\circ} \mathrm{C}$ in Sabouraud Dextrose Broth (SDB, Biolife) containing 20\% sterile glycerol. Before conducting the assays, each isolate was subcultured two or more times on SDA. Selected colonies ( $1 \mathrm{~mm}$ in dimater) were transferred to the sterile $0.85 \% \mathrm{NaCl}$. An optical density at $530 \mathrm{~nm}$ (OD530) for each isolate was adjusted to $0.08-0.10$ using $0.85 \% \mathrm{NaCl}$ sterile to give a standard inoculum of $1-5 \times 10^{6} \mathrm{CFU} / \mathrm{mL}$ (22).

\section{Antifungal susceptibility of fluconazole}

The disk diffusion (CLSI M44-A2) and broth microdilution (CLSI M27-A3 and CLSI M27-S4) methods were used to test antifungal susceptibility of fluconazole against $C$. albicans. Results of susceptibility of isolates to fluconazole were analyzed using WHONET software (23).

\section{Antifungal susceptibility of menthol}

The susceptibility of menthol (M2772 Sigma-Aldrich Co. St. Louis, MO, USA) was measured according to the CLSI antifungal susceptibility method for yeasts (CLSI M27-A3 and CLSI M27-S4). After dissolving menthol in DMSO, one hundred $\mu \mathrm{L}$ of the two-fold dilution of menthol (range $0.0313-50 \mu \mathrm{g} / \mathrm{mL}$ ) were prepared into 96 -well plates in RPMI 1640 with L-glutamine and without bicarbonate (Sigma-Aldrich) supplemented with $2 \%$ glucose and MOPS buffer. C. albicans inoculum $\left(0.5-5 \times 10^{3} \mathrm{CFU} / \mathrm{mL}\right)$ was then inoculated into 96 -well plates and incubated for 24 hours at $35^{\circ} \mathrm{C}$. Growth (menthol-free) and sterility (medium alone) control wells were established on each test plate.

Relative MICs were measured at OD530 using a Stat Fax 303 Reader (Awareness Technology, Inc., USA). The lowest concentration in which $\geq 50 \%$ or $90 \%$ reduction of growth was evident considered to be a relative MIC. Fluconazole was used as a control $(22,23)$.

\section{Candida albicans hypha formation}

Candida albicans ATCC MYA-573 was induced to form hypha formation according to the method described by Khodavandi et al (24). For hypha formation, $4 \mathrm{~mL}$ of menthol and fluconazole at $2 \times$ MIC and $1 \times$ MIC were prepared in 6-cm Petri dishes and $4 \mathrm{~mL}$ of C. albicans inoculum $\left(1-5 \times 10^{6} \mathrm{CFU} / \mathrm{mL}\right)$ was added on the Petri dishes. The dishes were incubated at $35^{\circ} \mathrm{C}$ for 90 minutes and the mixture was then incubated at $35^{\circ} \mathrm{C}$ for 16 hours with gentle shaking. The hyphae were briefly washed in PBS and observed with a light microscope (Leica, DMRA II, Germany).

\section{Expression of Candida albicans SAP1}

The expression assay of SAP1 gene was conducted using relative quantitative Real time PCR (qRT-PCR) that was adapted from a previously described method (23). C. albicans ATCC MYA-573 treated with menthol and fluconazole was induced to form hypha formation. Total RNA was extracted using a RNeasy Mini Kit (Qiagen, Hilden, Germany) containing DNase I in accordance 
with manufacturer's instructions. RNA quality and quantity were determined by spectrophotometric in a NanoDrop ${ }^{\circledR}$ ND1000- spectrophotometer (NanoDrop Technologies Inc., Wilmington, DE) and electrophoresis on a formaldehyde-denaturing agarose gel. The first strand of cDNA was synthesized using $\mathrm{M}-\mathrm{MuLV}$ reverse transcriptase (Fermentas, USA) according to the manufacturer's instructions, using random hexamer oligonucleotides and total RNA $(0.5 \mu \mathrm{g})$. The qRT-PCR was performed using SYBR ${ }^{\text {TM }}$ Green qPCR Master Mix (Fermentas, EU) on a Bio-Rad MiniOpticonTM system (USA). The oligonucleotide primers used for qRT-PCR were listed in Table 1. The expression levels of SAP1 gene were calculated by comparative Ct method $\left(2^{-\Delta \mathrm{Ct}}\right.$ formula) after normalization with beta actin gene $(23,25)$.

\section{Statistical analysis}

All experiments were performed in duplicate or triplicate. Differences between specific means were analyzed by a one-way analysis of variance (ANOVA). Results are shown as the mean value \pm standard deviation (SD). Values of $P<0.05$ were considered to be significant. The SPSS software (version 21; SPSS Inc., Chicago, IL) was used for statistical analysis.

\section{Results}

Clinical isolates of $C$. albicans were identified by morphological and biochemical characterization. Of 100 healthy women at the end of the pregnancy, 30 C. albicans were isolated and identified. The antifungal susceptibility of fluconazole on the growth of clinical isolates of $C$. albicans (using disk diffusion and broth microdilution methods) is reported in Table 2. Out of clinical isolates of C. albicans, $100 \%$ were found to be fluconazole-resistant. Kappa coefficient showed that there was a high degree of agreement between disk inhibition zone diameter and MICs for fluconazole.

The broth microdilution results obtained for the menthol compared with fluconazole against clinical isolates of C. albicans are reported in Table 3. Menthol induced a significant growth inhibition compared with fluconazole for C. albicans. The results showed a $\mathrm{MIC}_{90}$ of $1.6-25 \mu \mathrm{g} / \mathrm{mL}$ for fluconazole-resistance isolates of $C$. albicans.

Findings from potency of menthol to inhibit hypha formation of the C. albicans ATCC MYA-573 exhibited a significant reduction in hyphae and planktonic cells compared to the untreated control. Figure 1 shows the inhibitory property of menthol on C. albicans ATCC MYA-573 hyphal formation at concentrations of $2 \times$ MIC and $1 \times$ MIC after 16 hours. The effect of fluconazole was not dramatically decreased hyphae and planktonic cells of fluconazole-resistant $C$. albicans compared to the untreated control.

QRT-PCR was performed to investigate the effect of menthol on the expression of SAP1 gene in fluconazoleresistance C. albicans cells (ATCC MYA-573). Box plots are shown in Figure 2. Fluconazole-resistance C. albicans cells showed significant changes in the expression levels of SAP1 compared to the untreated control $(P \leq 0.05)$. Treatment with fluconazole increased expression of SAP1 by 1.53 - and 1.43-fold at concentrations of $2 \times$ MIC and $1 \times$ MIC, respectively. In the fluconazole-resistance $C$. albicans cells treated with menthol the expression levels of SAP1 were down regulated by 2.02 - and 1.85 -fold at concentrations of $2 \times$ MIC and $1 \times$ MIC, respectively $(P$ $\leq 0.05)$.

\section{Discussion}

Fluconazole resistance has been identified as the main cause of treatment failure of candidiasis $(27,28)$. Considering a major clinical challenge of antifungal resistance, the antimicrobial potential of the natural products can be regarded as a precious resource. In this study, we showed that menthol displays a potential antiCandida activity. The antifungal activities of menthol are

Table 1. Oligonucleotide primer sequences used for $q R T-P C R$

\begin{tabular}{llll}
\hline Primer & Orientation & Sequence & Reference \\
\hline SAP1 & Forward & 5' TTTCATCGCTCTTGCTATTGCTT 3' & $(6)$ \\
& Reverse & 5' TGACATCAAAGTCTAAAGTGACAAAACC 3' & \\
ACT & Forward & 5' GAGTTGCTCCAGAAGAACATCCAG 3' & (26) \\
& Reverse & 5' TGAGTAACACCATCACCAGAATCC 3' & \\
\hline
\end{tabular}

Table 2. Results susceptibility of fluconazole using disk diffusion and broth microdilution methods against Candida albicans vaginal isolates in pregnant women

\begin{tabular}{|c|c|c|c|c|c|c|c|c|c|c|c|c|c|c|c|}
\hline \multirow{2}{*}{$\begin{array}{l}\text { Susceptibility } \\
\text { method }\end{array}$} & \multirow{2}{*}{$\begin{array}{l}\text { Antibiotic } \\
\text { name }\end{array}$} & \multirow[t]{2}{*}{$\mathbf{N}$} & \multirow[t]{2}{*}{$\% R$} & \multirow[t]{2}{*}{$\% 1$} & \multirow[t]{2}{*}{$\% S$} & \multirow[t]{2}{*}{$\% \mathrm{R} 95 \% \mathrm{Cl}$} & \multirow{2}{*}{$\begin{array}{l}\text { Geom. } \\
\text { Mean }\end{array}$} & \multirow{2}{*}{$\begin{array}{l}\text { MIC range } \\
\mu \mathrm{g} / \mathrm{mL}\end{array}$} & \multicolumn{4}{|c|}{$\begin{array}{l}\text { Disk zone diameter }(\mathrm{mm}) \\
\text { distribution }\end{array}$} & \multicolumn{3}{|c|}{$\begin{array}{l}\text { MIC90 }(\mu \mathrm{g} / \mathrm{mL}) \\
\text { distribution }\end{array}$} \\
\hline & & & & & & & & & 9 & 10 & 11 & 12 & 16 & 32 & 64 \\
\hline Disk diffusion & Fluconazole & 30 & 100 & 0 & 0 & $85.9-100$ & - & - & $33.3 \%$ & $20 \%$ & $43.3 \%$ & $3.3 \%$ & - & - & - \\
\hline Broth microdilution & Fluconazole & 30 & 100 & 0 & 0 & $85.9-100$ & 27.857 & $8-64$ & - & - & - & - & $40 \%$ & $40 \%$ & $20 \%$ \\
\hline
\end{tabular}


Table 3. Relative MIC ( $\mu \mathrm{g} / \mathrm{mL})$ values of menthol against Candida albicans vaginal isolates in pregnant women

\begin{tabular}{|c|c|c|c|c|}
\hline \multirow{2}{*}{ Isolates / Antifungals } & \multicolumn{2}{|c|}{ Menthol } & \multicolumn{2}{|c|}{ Fluconazole } \\
\hline & $\mathrm{MIC}_{90}$ & $\mathrm{MIC}_{50}$ & $\mathrm{MIC}_{90}$ & $\mathrm{MIC}_{50}$ \\
\hline C. albicans ATCC 14053 & $6.50 \pm 0.04$ & $1.60 \pm 0.02$ & $4.00 \pm 0.08$ & $1.00 \pm 0.06$ \\
\hline C. albicans ATCC MYA-573 & $3.10 \pm 0.01$ & $0.80 \pm 0.02$ & $64.00 \pm 0.70$ & $16.00 \pm 0.08$ \\
\hline $\mathrm{Cl}-1$ & $12.50 \pm 0.20$ & $3.10 \pm 0.02$ & $16.00 \pm 0.10$ & $2.00 \pm 0.02$ \\
\hline $\mathrm{Cl}-2$ & $25.00 \pm 0.15$ & $3.10 \pm 0.02$ & $32.00 \pm 0.10$ & $5.00 \pm 0.01$ \\
\hline $\mathrm{Cl}-3$ & $12.50 \pm 0.03$ & $1.60 \pm 0.02$ & $64.00 \pm 0.01$ & $16.00 \pm 0.10$ \\
\hline $\mathrm{Cl}-4$ & $12.50 \pm 0.01$ & $1.60 \pm 0.02$ & $64.00 \pm 0.03$ & $5.00 \pm 0.02$ \\
\hline $\mathrm{Cl}-5$ & $12.50 \pm 0.05$ & $3.10 \pm 0.01$ & $64.00 \pm 0.02$ & $16.00 \pm 0.08$ \\
\hline $\mathrm{Cl}-6$ & $3.10 \pm 0.01$ & $1.60 \pm 0.04$ & $16.00 \pm 0.03$ & $8.00 \pm 0.03$ \\
\hline $\mathrm{Cl}-7$ & $3.10 \pm 0.04$ & $1.60 \pm 0.01$ & $32.00 \pm 0.10$ & $4.00 \pm 0.03$ \\
\hline $\mathrm{Cl}-8$ & $3.10 \pm 0.04$ & $0.80 \pm 0.02$ & $16.00 \pm 0.02$ & $2.00 \pm 0.02$ \\
\hline $\mathrm{Cl}-9$ & $3.10 \pm 0.01$ & $0.80 \pm 0.01$ & $32.00 \pm 0.05$ & $2.00 \pm 0.01$ \\
\hline $\mathrm{Cl}-10$ & $12.50 \pm 0.04$ & $3.10 \pm 0.02$ & $32.00 \pm 0.10$ & $5.00 \pm 0.02$ \\
\hline $\mathrm{Cl}-11$ & $12.50 \pm 0.04$ & $6.50 \pm 0.02$ & $16.00 \pm 0.10$ & $8.00 \pm 0.09$ \\
\hline $\mathrm{Cl}-12$ & $12.50 \pm 0.02$ & $3.10 \pm 0.05$ & $32.00 \pm 0.50$ & $2.00 \pm 0.06$ \\
\hline $\mathrm{Cl}-13$ & $3.10 \pm 0.04$ & $0.80 \pm 0.02$ & $16.00 \pm 0.40$ & $2.00 \pm 0.05$ \\
\hline $\mathrm{Cl}-14$ & $1.60 \pm 0.01$ & $0.80 \pm 0.02$ & $32.00 \pm 0.30$ & $2.00 \pm 0.01$ \\
\hline $\mathrm{Cl}-15$ & $12.50 \pm 0.05$ & $1.60 \pm 0.04$ & $64.00 \pm 0.50$ & $10.00 \pm 0.10$ \\
\hline $\mathrm{Cl}-16$ & $12.50 \pm 0.01$ & $1.60 \pm 0.02$ & $32.00 \pm 0.20$ & $5.00 \pm 0.06$ \\
\hline $\mathrm{Cl}-17$ & $25.00 \pm 0.01$ & $6.50 \pm 0.02$ & $16.00 \pm 0.05$ & $4.00 \pm 0.05$ \\
\hline $\mathrm{Cl}-18$ & $12.50 \pm 0.01$ & $3.10 \pm 0.02$ & $64.00 \pm 0.04$ & $2.00 \pm 0.03$ \\
\hline $\mathrm{Cl}-19$ & $6.50 \pm 0.01$ & $3.10 \pm 0.05$ & $16.00 \pm 0.03$ & $1.00 \pm 0.07$ \\
\hline $\mathrm{Cl}-20$ & $25.00 \pm 0.02$ & $12.50 \pm 0.02$ & $32.00 \pm 0.10$ & $2.00 \pm 0.06$ \\
\hline $\mathrm{Cl}-21$ & $12.50 \pm 0.04$ & $3.10 \pm 0.04$ & $16.00 \pm 0.09$ & $1.00 \pm 0.02$ \\
\hline $\mathrm{Cl}-22$ & $12.50 \pm 0.04$ & $1.60 \pm 0.04$ & $16.00 \pm 0.30$ & $4.00 \pm 0.02$ \\
\hline $\mathrm{Cl}-23$ & $6.50 \pm 0.02$ & $1.60 \pm 0.01$ & $32.00 \pm 0.10$ & $4.00 \pm 0.02$ \\
\hline $\mathrm{Cl}-24$ & $3.10 \pm 0.04$ & $0.80 \pm 0.02$ & $16.00 \pm 0.06$ & $1.00 \pm 0.04$ \\
\hline $\mathrm{Cl}-25$ & $3.10 \pm 0.01$ & $0.40 \pm 0.02$ & $16.00 \pm 0.40$ & $5.00 \pm 0.06$ \\
\hline $\mathrm{Cl}-26$ & $12.50 \pm 0.04$ & $0.80 \pm 0.02$ & $32.00 \pm 0.20$ & $4.00 \pm 0.06$ \\
\hline $\mathrm{Cl}-27$ & $12.50 \pm 0.01$ & $1.60 \pm 0.02$ & $32.00 \pm 0.15$ & $2.00 \pm 0.05$ \\
\hline $\mathrm{Cl}-28$ & $12.50 \pm 0.01$ & $6.50 \pm 0.05$ & $64.00 \pm 0.08$ & $10.00 \pm 0.09$ \\
\hline $\mathrm{Cl}-29$ & $25.00 \pm 0.04$ & $3.10 \pm 0.04$ & $32.00 \pm 0.05$ & $2.00 \pm 0.06$ \\
\hline $\mathrm{Cl}-30$ & $12.50 \pm 0.02$ & $1.60 \pm 0.02$ & $16.00 \pm 0.06$ & $2.00 \pm 0.04$ \\
\hline
\end{tabular}

$\mathrm{Cl}$ : C. albicans vaginal isolates in pregnant women.

reported in research studies and within the context of existing literature (17-20).

The results presented in this paper showed 100\% of resistancy in C. albicans vaginal isolates to fluconazole. These results are corroborated by the literature, citing fluconazole-resistant C. albicans (27-29). Fluconazole is a fungistatic rather than fungicidal medication and hence provides the opportunity for acquired resistance in certain fungi (29). Our data support the effects of menthol in fluconazole-resistant $C$. albicans vaginal isolates. Several lines of evidence demonstrate that natural pure compounds derived from plants are the most potent products to kill antifungal resistant C. albicans $(23,30)$.

Our results showed that the antifungal activity of menthol on the fluconazole-resistant $C$. albicans is able to inhibit hyphal formation with a decreasing in the ability of $C$. albicans cells to adhere to host cell surfaces.
Following hyphal formation, C. albicans hyphae secreted of hydrolases are thought to enhance the efficiency of nutrient uptake. In fact, Saps degrades host proteins, penetrates into the surrounding tissues and finally evades host immune defenses (31). However, the SAP genes play key roles in virulence of $C$. albicans required for infections (3-6). In the present study, the relative gene expression analyses were performed to investigate the possible effects of menthol at molecular level. The main changes in the gene expression induced by treatments with menthol were down regulated SAP1. These results are in agreement with those reported in the literature regarding the effects of antifungal agents on the expression of SAP1 $(24,30,32)$. Samaranayake et al. (33) indicated that the expression levels of SAP1, SAP4, SAP6, SAP8-SAP10 genes were significantly higher in the C. albicans SC5314 biofilms than in the controls. 

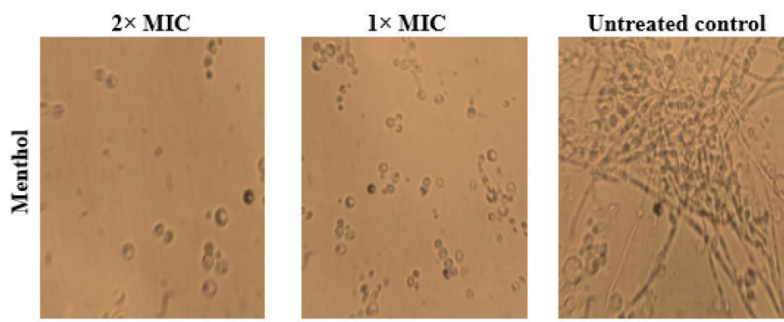

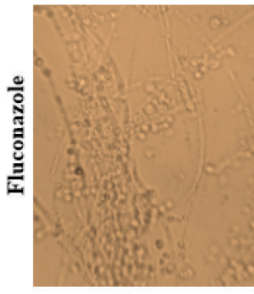

$50 \mu \mathrm{m}$

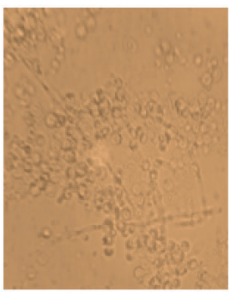

$50 \mu \mathrm{m}$

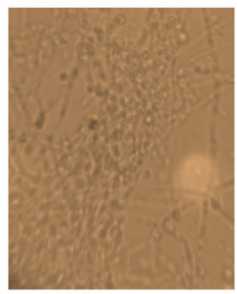

$50 \mu \mathrm{m}$
Figure 1. Effect of menthol and fluconazole at concentrations of $2 \times$ MIC and $1 \times$ MIC on Candida albicans ATCC MYA-573 hypha formation under light microscope at $40 x$ magnification, $B a r=50$ $\mu \mathrm{m}$.

In conclusion, our study demonstrated the efficacy of menthol on inhibition of growth, reduction of hyphal formation and down regulation SAP1 against fluconazoleresistance C. albicans. As fluconazole-resistance C. albicans is one of the most alarming health issues, this study suggests that menthol may have potential applications in the treatment of infections due to these resistant fungi. In spite of our certainty that the best results are obtained by menthol, further investigation may be focused on the menthol's effcets on other significant genes contributing to the cell pathogenesis of C. albicans.

\section{Acknowledgements}

The authors are thankful to the Islamic Azad University of Gachsaran for providing all the facilities for this study. Results of the current study are part of the MSc thesis (14930513952001) of Shahrzad Shayegan.

\section{Authors' contributions}

SS carried out the experiments. AK designed the experiment, managed the literature searches and produced the initial draft. All authors read and approved the final version of the manuscript.

\section{Conflict of interest}

The authors declared no competing interests.

\section{Ethical considerations}

This study was approved by Research Ethics Committee of our institute (Ethical code 14930513952001). The study protocol conformed to the ethical guidelines of the 2008 Declaration of Helsinki.

\section{Funding/Support}

None.
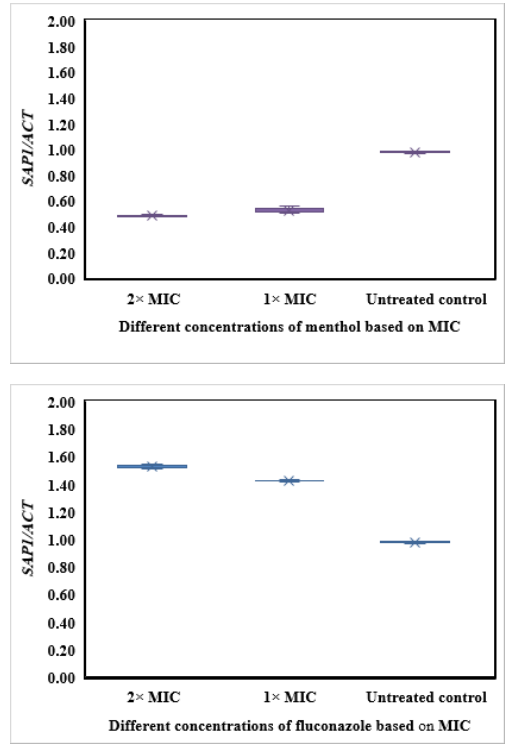

Figure 2. Box plots of SAP1/ACT ratio at different concentrations of menthol and fluconazole based on MIC in Candida albicans ATCC MYA-573.

\section{References}

1. Spampinato C, Leonardi D. Candida infections, causes, targets, and resistance mechanisms: traditional and alternative antifungal agents. Biomed Res Int. 2013;2013:204237. doi: $10.1155 / 2013 / 204237$.

2. Singh S, Fatima Z, Hameed S. Predisposing factors endorsing Candida infections. Infez Med. 2015;23(3):21123.

3. Naglik JR, Challacombe SJ, Hube B. Candida albicans secreted aspartyl proteinases in virulence and pathogenesis. Microbiol Mol Biol Rev. 2003;67(3):400-28. doi: 10.1128/ MMBR.67.3.400-428.2003.

4. Schaller M, Bein M, Korting HC, Baur S, Hamm G, Monod M, et al. The secreted aspartyl proteinases Sap1 and Sap2 cause tissue damage in an in vitro model of vaginal candidiasis based on reconstituted human vaginal epithelium. Infect Immun. 2003;71(6):3227-34. doi: 10.1128/IAI.71.6.3227-3234.2003.

5. Correia A, Lermann U, Teixeira L, Cerca F, Botelho S, da Costa RM, et al. Limited role of secreted aspartyl proteinases Sap1 to Sap6 in Candida albicans virulence and host immune response in murine hematogenously disseminated candidiasis. Infect Immun. 2010;78(11):483949. doi: 10.1128/IAI.00248-10.

6. Naglik JR, Moyes D, Makwana J, Kanzaria P, Tsichlaki E, Weindl G, et al. Quantitative expression of the Candida albicans secreted aspartyl proteinase gene family in human oral and vaginal candidiasis. Microbiology. 2008;154(Pt 11):3266-80. doi: 10.1099/mic.0.2008/022293-0.

7. Staniszewska M, Bondaryk M, Zukowski K, Chudy M. Role of SAP7-10 and morphological regulators (EFG1, CPH1) in Candida albicans' hypha formation and adhesion to Colorectal Carcinoma Caco-2. Pol J Microbiol. 2015;64(3):203-10.

8. Staniszewska M, Bondaryk M, Siennicka K, Kurek A, Orłowski J, Schaller M, et al. In vitro study of secreted 
aspartyl proteinases Sap1 to Sap3 and Sap4 to Sap6 expression in Candida albicans pleomorphic forms. Pol J Microbiol. 2012;61(4):247-56.

9. Cassone A, Vecchiarelli A, Hube B. Aspartyl proteinases of eukaryotic microbial pathogens: from eating to heating. PLoS Pathog. 2016;12(12):e1005992. doi: 10.1371/journal. ppat.1005992.

10. Monroy-Pérez E, Paniagua-Contreras G, Vaca-Paniagua F, Negrete-Abascal E. SAP expression in Candida albicans strains isolated from Mexican patients with vaginal candidosis. Int J Clin Med. 2013;4(1):25-31. doi. 10.4236/ ijcm.2013.41006.

11. Zawrotniak M, Bochenska O, Karkowska-Kuleta J, SewerynOzog K, Aoki W, Ueda M, et al. Aspartic proteases and major cell wall components in Candida albicans trigger the release of neutrophil extracellular traps. Front Cell Infect Microbiol. 2017;7:414. doi: 10.3389/fcimb.2017.00414.

12. Hube B, Turver CJ, Odds FC, Eiffert H, Boulnois GJ, Köchel $\mathrm{H}$, et al. Sequence of the Candida albicans gene encoding the secretory aspartate proteinase. J Med Vet Mycol. 1991;29(2):129-32.

13. White TC, Miyasaki SH, Agabian N. Three distinct secreted aspartyl proteinases in Candida albicans. J Bacteriol. 1993;175(19):6126-33.

14. De Bernardis F, Sullivan PA, Cassone A. Aspartyl proteinases of Candida albicans and their role in pathogenicity. Med Mycol. 2001;39(4):303-13.

15. Mishra NN, Prasad T, Sharma N, Payasi A, Prasad R, Gupta DK, et al. Pathogenicity and drug resistance in Candida albicans and other yeast species. Acta Microbiol Immunol Hung. 2007;54(3):201-35. doi:10.1556/AMicr.54.2007.3.1.

16. Shor E, Perlin DS. Coping with stress and the emergence of multidrug resistance in fungi. PLoS Pathog. 2015;11(3):e1004668. doi: 10.1371/journal.ppat.1004668.

17. Sharifzadeh A, Khosravi AR, Shokri H, Tari PS. Synergistic anticandidal activity of menthol in combination with itraconazole and nystatin against clinical Candida glabrata and Candida krusei isolates. Microb Pathog. 2017;107:3906. doi: 10.1016/j.micpath.2017.04.021.

18. Suchodolski J, Feder-Kubis J, Krasowska A. Antifungal activity of ionic liquids based on (-)-menthol: a mechanism study. Microbiol Res. 2017;197:56-64. doi: 10.1016/j. micres.2016.12.008.

19. Pemmaraju SC, Pruthi PA, Prasad R, Pruthi V. Candida albicans biofilm inhibition by synergistic action of terpenes and fluconazole. Indian J Exp Biol. 2013;51(11):1032-7.

20. Abbaszadeh S, Sharifzadeh A, Shokri H, Khosravi AR, Abbaszadeh A. Antifungal efficacy of thymol, carvacrol, eugenol and menthol as alternative agents to control the growth of food-relevant fungi. J Mycol Med. 2014;24(2):e516. doi: 10.1016/j.mycmed.2014.01.063.

21. Trombetta D, Castelli F, Sarpietro MG, Venuti V, Cristani
M, Daniele C, et al. Mechanisms of antibacterial action of three monoterpenes. Antimicrob Agents Chemother. 2005;49(6):2474-8. doi: 10.1128/AAC.49.6.2474-2478.2005.

22. Alizadeh F, Khodavandi A, Zalakian S. Quantitation of ergosterol content and gene expression profile of ERG11 gene in fluconazole-resistant Candida albicans. Curr Med Mycol. 2017; 3(1):13-19. doi: 10.29252/cmm.3.1.13.

23. Khodavandi A, Alizadeh F, Sanaee T. Antifungal activity of carvacrol on ergosterol synthesis in multidrug resistant Candida albicans. Medical J Hormozgan Univ Med Sci. 2018;22(2):113-21.

24. Khodavandi A, Alizadeh F, Harmal NS, Sidik SM, Othman F, Sekawi Z, et al. Expression analysis of SIR2 and SAPs14 gene expression in Candida albicans treated with allicin compared to fluconazole. Trop Biomed. 2011;28(3):589-98.

25. Schmittgen TD, Livak KJ. Analyzing real-time PCR data by the comparative $\mathrm{C}(\mathrm{T})$ method. Nat Protoc. 2008;3(6):1101-8.

26. Lim CS, Wong WF, Rosli R, Ng KP, Seow HF, Chong PP. 2-dodecanol (decyl methyl carbinol) inhibits hyphal formation and SIR2 expression in Candida albicans. J Basic Microbiol. 2009;49(6):579-83. doi: 10.1002/ jobm.200900035.

27. Ostrosky-Zeichner L, Harrington R, Azie N, Yang H, Li $\mathrm{N}$, Zhao J, et al. A Risk score for fluconazole failure among patients with candidemia. Antimicrob Agents Chemother. 2017;61(5):e02091-16. doi: 10.1128/AAC.02091-16.

28. Berkow EL, Lockhart SR. Fluconazole resistance in Candida species: a current perspective. Infect Drug Resist. 20171;10:237-245. doi: 10.2147/IDR.S118892.

29. Salehei Z, Seifi Z, Zarei Mahmoudabadi A. Sensitivity of vaginal isolates of Candida to eight antifungal drugs isolated from Ahvaz, Iran. Jundishapur J Microbiol. 2012;5(4):5747.

30. Hosseini SS, Yadegari MH, Rajabibazl M, Ghaemi EA. Inhibitory effects of carvacrol on the expression of secreted aspartyl proteinases 1-3 in fluconazole-resistant Candida albicans isolates. Iran J Microbiol. 2016;8(6):401-9.

31. Chin VK, Lee TY, Rusliza B, Chong PP. Dissecting Candida albicans infection from the perspective of C. albicans virulence and omics approaches on host-pathogen interaction: a review. Int J Mol Sci. 2016;17(10):1643. doi: 10.3390/ijms17101643.

32. Khodavandi A, Alizadeh F, Alizadeh E. Antifungal activity of carvacrol in combination with fluconazole or amphotericin B against Candida albicans. Malays J Microbiol. 2018;14(5):356-63.

33. Samaranayake YH, Cheung BP, Yau JY, Yeung SK, Samaranayake LP. Human serum promotes Candida albicans biofilm growth and virulence gene expression on silicone biomaterial. PLoS One. 2013;8(5):e62902. doi: 10.1371/journal.pone.0062902. 